\title{
Review Article \\ Reliability and Fatigue Analysis in Cantilever-Based MEMS Devices Operating in Harsh Environments
}

\author{
Mohammad Tariq Jan, ${ }^{1,2}$ Nor Hisham Bin Hamid, ${ }^{1}$ Mohd Haris Md Khir, ${ }^{1}$ \\ Khalid Ashraf, ${ }^{1}$ and Mohammad Shoaib ${ }^{1}$ \\ ${ }^{1}$ Department of Electrical and Electronics Engineering, Universiti Teknologi, PETRONAS, 31750 Seri Iskandar, Tronoh, Perak, Malaysia \\ ${ }^{2}$ Department of Physics, Kohat University of Science and Technology (KUST), Kohat 26000, Pakistan \\ Correspondence should be addressed to Mohammad Tariq Jan; tariqjan@kust.edu.pk
}

Received 30 August 2013; Revised 1 December 2013; Accepted 1 December 2013; Published 12 January 2014

Academic Editor: Adiel Teixeira de Almeida

Copyright (C) 2014 Mohammad Tariq Jan et al. This is an open access article distributed under the Creative Commons Attribution License, which permits unrestricted use, distribution, and reproduction in any medium, provided the original work is properly cited.

\begin{abstract}
The microelectromechanical system (MEMS) is one of the most diversified fields of microelectronics; it is rated to be the most promising technology of modern engineering. MEMS can sense, actuate, and integrate mechanical and electromechanical components of micro- and nano sizes on a single silicon substrate using microfabrication techniques. MEMS industry is at the verge of transforming the semiconductor world into MEMS universe, apart from other hindrances; the reliability of these devices is the focal point of recent research. Commercialization is highly dependent on the reliability of these devices. MEMS requires a high level of reliability. Several technological factors, operating conditions, and environmental effects influencing the performances of MEMS devices must be completely understood. This study reviews some of the major reliability issues and failure mechanisms. Specifically, the fatigue in MEMS is a major material reliability issue resulting in structural damage, crack growth, and lifetime measurements of MEMS devices in the light of statistical distribution and fatigue implementation of Paris' law for fatigue crack accumulation under the influence of undesirable operating and environmental conditions.
\end{abstract}

\section{Introduction}

The microelectromechanical system (MEMS) is a rapidly evolving technology that incorporates electrical and mechanical elements at the microlevel. Due to the small size of MEMS devices, this technology has been widely appreciated in almost every field of life. MEMS devices possess a simple principle of operation and are easy to fabricate. The electronic components are fabricated using traditional integrated circuits (ICs) fabrication technology, while the mechanical parts are fabricated by using silicon and other substrates utilizing micromachining processes. Bulk [1] and surface micromachining [2] are the two main processes adopted for the fabrication of the mechanical parts of MEMS devices. The fabrication techniques, such as microfabrication, micromachining, and ICs, involve components that can range in size from the submicrometer level to the millimeter level [3]. The MEMS industries are constantly improving the design and fabrication techniques of these devices.
MEMS, by virtue of its nature, corresponds to a distinctive technology that has transformed the entire MEMS industry. Bulky sensors and actuators can be replaced by miniaturized MEMS devices. MEMS accelerometers are frequently used in automobiles for air bag deployment; blood pressure sensors, microsyringes, and implantable biosensors in the medical and life sciences; inkjet printer heads, computer disks, projection displays; and microvalves used in electronics, communication, and defense [4-7]. Apart from these, many other MEMS products are manufactured for various industrial and consumer applications.

MEMS devices mainly consist of sensors and actuators collectively called transducers are capable of converting one form of energy into another form. MEMS technologies are merged with microelectronics and optical systems to form the microoptoelectromechanical system (MOEMS) and the nanoelectromechanical system (NEMS) on a single silicon chip [8-10]. Advancement in the MEMS technology is on the move and is well recognized and respected by 
the academicians, research laboratories, and industry; however, in spite of its global recognition, the reliable design of MEMS devices is one of the main challenges in the commercialization of these devices [11-13]. The reliability of MEMS is neither well established nor recognized by the industry and academia [14] and is accepted as a relatively new and challenging field for research. In the long run, MEMS may support novel classes of exceptionally small, fast, selfmanaging, and cost effective devices [14]. In order to gain a high volume market place, it is essential that MEMS devices should be of competitive reliability.

The main goal of reliable MEMS designing is to come up with devices having mechanical components as reliable as its electrical parts. Since MEMS technology is growing and many more applications are entering into the mainstream of MEMS devices, it is important to understand the reliability issues in these devices. Research in MEMS is mainly focused on the design methodologies and fabrication techniques in order to produce miniature and effective MEMS devices [15-17]. Because of the basic building structure of MEMS, the working environments of MEMS sensors and actuators may not be suitable for the electronics counterpart of the whole assembly and hence can affect its performance. The reliability of MEMS devices has not been addressed as a major degradation factor in the performances of these devices at commercial as well as at consumer levels [11]. In MEMS technology, the trend towards constantly reducing the size and volume, intercommunication, and multiple dimensions is making them as devices of choice. However, the failure of the mechanisms due to the introduction of new processes, designs, and materials as well as the fabrication techniques is making MEMS devices unreliable [18, 19]. Product replacement costs have driven the need for improved reliability, which has led to design tradeoffs [20]. On the other hand, reliability is a challenge for MEMS manufacturers due to the growing market and stricter government safety regulations [17]. MEMS applications are expanding; in fact, the MEMS market is currently double that of ICs and is expected to be US\$20 billion in 2017 [21]. All MEMS devices have dissimilar applications; nevertheless, they share some common requirements, such as (1) time to market that leads to success, (2) stress reduction, and (3) reliability of MEMS being critical [22].

Design optimization of MEMS sensors and actuators is critical due to high cost lengthy fabrication processes. Vagueness in the fabrication and etching processes used to manufacture MEMS devices can lead to certain uncertainties in the performance of final product consequently obtaining low yield and poor reliability [23]. The reliability study of MEMS devices is therefore essential. Due to complex nature of MEMS devices, the reliability must be considered as a separate field of research. The research on reliability will grow as the MEMS technology attains its height. Temperature and humidity are reported as two major reliability issues of MEMS devices [24]. The reason is that there are many sensors and actuators that are exposed to the harsh environments, such as accelerometers, gyroscopes, thermal actuators, and chemical sensors. This paper mainly discusses fatigue generation and the operational and environmental effects on the performances of cantilever-based MEMS devices. Particularly, fatigue being a material reliability issue that hinders the performance of cantilevers-based MEMS is focused on. Fatigue induced due to the crack growth rate, and the lifetime of MEMS devices can be modeled through statistical distribution functions and Paris' law.

This paper presents a review of the current literature on the reliability of MEMS. Section 2 discusses reliability and its importance. Section 3 describes the failure mechanisms of MEMS devices followed by fatigue and then the crack growth modeling of fatigue. A thorough review of the environmental effects on the cantilever-based MEMS devices is presented in Section 4.

\section{Reliability}

Due to the most promising technology of the modern engineering sciences MEMS has brought revolution to the silicon industry. Most of the MEMS components are being fabricated using silicon and its oxides. However, regardless of the brighter future of MEMS, it materializes to be in an alarming state. In order to underline MEMS reliability concerns, it is endeavored that a complete knowledge of the failure mechanism (physics and statistics) is fully understood. Due to continued intensification of the MEMS family, the overall costs of manufacturing, failure rates, and its performances over the accepted period of time (reliability) are the significant issues that can be resolved at the time of manufacturing. Being an emerging technology MEMS reliability is of prime importance in applications where the failure can be fatal and shocking [25]. A variety of materials are used in the fabrication of MEMS devices. Materials showing improved tendency in the direction of high reliability and long term survivability are taken as the material of choice, even if it increases the overall cost of the device [26].

MEMS manufacturers are going to come across a challenging task in addressing the reliability of MEMS devices for the reason of their versatility both at the production and application levels [17]. Reliability is the ability of a MEMS device to perform its intended function without failure under stated conditions for a particular period of time. The performance of MEMS devices is highly dependent on the compatibility of several static and moving parts, the design, and the selection of materials where the device can perform the desired function with long term repeatability and accuracy [27]. The growing density of MEMS products, demands for multiple functions on the same chip, and its operation in multiple domains are indeed making the reliability of MEMS devices a challenging task. Traditional approaches are being used for the design and fabrication of MEMS devices, and less attention has been diverted to address the reliability issues [27]. As reliability is becoming the subject of research for the upcoming MEMS generation, emphasis on the identification and rectification of the reliability issues of MEMS devices is a big issue for the researchers, academicians, and industry. Particularly the mechanical reliability of the material of which MEMS devices are being fabricated is one of the most important aspects when dealing with reliability of these devices. Therefore it is being treated as a new phenomenon 
and at the eve of new developments in the evaluation of experimental procedures and analysis which have resulted in further enhancements in the field of reliability of MEMS devices.

Three challenges are considered in MEMS reliability:

(1) finding the correct failure mechanism,

(2) obtaining statistically significant data,

(3) defining the physical model of MEMS.

Research into the MEMS failure mechanism is in its very early stages and cannot be trusted [20,28]. The electronic industry also acknowledges the importance of reliability in MEMS across several consumer applications [29]. The root causes of failure of reliability in MEMS devices are extremely product dependent. Sufficient technical data has not been available on the basis of which specific and general failure mechanisms of MEMS devices can be targeted. A standard test method is needed for characterizing the mechanical properties of MEMS devices produced by the same processes and at the same scales as the intended application. Further studies on reliability suggest that it is the ability to sort out good devices from bad ones [28] and quantitatively predict the failure rate in devices before they are delivered to the customer [20]. The commercialization of MEMS is directly proportional to the reliability of MEMS. Moreover, MEMS products being well guarded trade secrets and restrictions on sharing knowledge and experience have resulted in the slow growth of the MEMS industry [11]. On the other hand, MEMS is multifunctional which causes failures that vary significantly from device to device. Reliable MEMS devices are key to successful commercialization [11]. In spite of extensive research being in progress, only the digital micromirror device (DMD) for digital projectors from Texas Instruments, analog devices accelerometer for air bag deployment, Gyroscope in iphones from STMicroelectronics, and Inkjet printer heads from Hewlett-Packard (HP) have made their way to successful commercialization [4-6]. Some common MEMS devices and their reliability issues are listed: accelerometer suffers from mechanical wear, fractures, fatigue, and charging and friction. Vibration, shock, fractures, and fatigue were found in pressure sensors, whereas the gyroscopes' reliability issues include charging, shock, and vibrations [29-32]. Various reliability test methods and approaches have been adopted by many researchers and research laboratories and can be seen in $[28,33-40]$. An experimental model analysis methodology has been investigated for microsystems emphasizing the shortage of techniques required to quantify the reliability of MEMS [3]. Research on reliability mainly focuses on the prediction of the failure mechanism in MEMS devices [41]. Several reports were documented on the response times and linearity of the output signal subjected to shock loads $[42,43]$. MEMS microengines were exposed to harsh environments by testing shock pulses for various amplitudes $[19,44]$. The main emphases of these studies were to observe the impact of shocks under loading conditions; some wrecked mechanical components were found as a result of unbearable shocks during loading cycles.

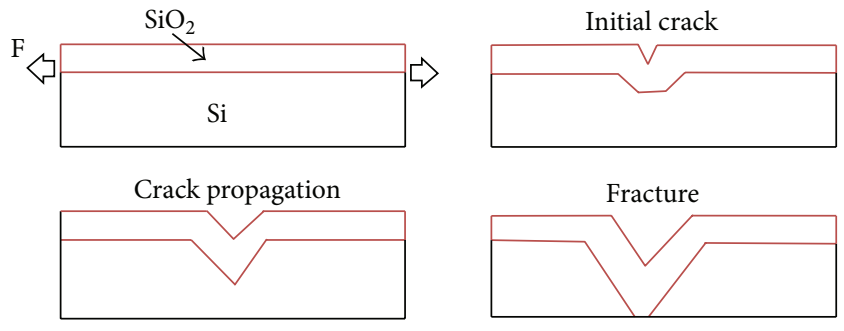

FIGURE 1: SCC formation on the silicon substrate subjected to tensile stresses [46].

Corrosion has been identified as one of the reliability degrading factors. It can cause a mechanical fracture in the form of scratches, inclusion, and environmentally assisted cracks [45]. Moisture and temperature have been found to enhance corrosion in metals, such as aluminum, where stress corrosion cracks (SCC) occur on the surface of the material on the area of the maximum stress. SCC is also found in silicon which is covered with a thin oxide layer in air and results in the crack initialization that is enhanced under variations in stresses. As cracks proceed, the silicon interfaces the oxides deep into the structure enhancing the crack growth until the final fracture occurs; this phenomena can be seen in Figure 1 [46].

Wear plays a vital role towards the poor reliability of MEMS devices; it is associated with rubbing or impacting surfaces and is responsible of four types of failure in MEMS devices, for example, adhesion, abrasion, corrosion, and surface fatigue $[12,47]$. It has been experimentally observed that the adhered length, rest time, temperature, relative humidity, and sliding velocity are some common factors contributing to the poor reliability in MEMS devices specially those containing microcantilevers $[48,49]$. Wear in MEMS can be prevented from occurring by introducing protecting borders to the MEMS structures. These borders can be in the form of solid films, antistiction coatings, gas phase lubrication, or diamond like coatings (DLC) $[50,51]$. To protect the surface of the MEMS structure from wear, a thin film, such as perfluorodecyltrichlorosilane, is coated on the surface of the MEMS structure [52]. Contamination is another factor that can hinder the performances of MEMS devices. The induction of unintended materials and contamination alters the mechanical movements of MEMS devices thus resulting in failure $[15,53]$.

Electric short and open circuits are valid factors that contribute to poor reliability. Unfortunately, this phenomena has been mixed with the semiconductor technology in treating reliability issues in ICs, whereas MEMS are different from semiconductor devices. The dielectric properties of silicon in MEMS are still not fully understood [7]. Dielectric degradation, charge injection, Ohmic contacts, electromigration, and electric stress are typical examples and causes of problems in device performances. An electrostatic discharge (ESD) causes almost 25\% of failures in MEMS devices that includes gate oxidation breakdown, junction spiking, and latchup [54]. In MEMS, the dielectric is involved in sacrificial, structural, optical, masking, passivation, insulator, and encapsulation 
layers. ESD related problems in the dielectric are fatal [5557]. Sources of ESD include the human body, charge devices, charged environments, and cosmic rays. The human body can build up an electric potential more than 1000 volts, which can prove to be fatal for MEMS devices [58]. Numerous test standards, experimental procedures, and processes have been demonstrated to overcome the open, short circuit and ESD problems [59, 60]. However, this area still requires more attention from researchers and academicians in order to rectify the reliability issues in these sophisticated MEMS devices.

The packaging of MEMS devices is an important factor that also contributes to poor reliability, due to the unique construction of MEMS devices and their interaction with the surroundings in certain ways. Therefore, it requires a nonstandard packaging. Standard hermetic packaging used for microelectronic circuits is not useful for most of the MEMS devices [13]. It has been observed that MEMS and NEMS having moving parts (for sensing and actuation) have to be free but inside a package; alternatively an unpackaged MEMS is a dead MEMS [61].

2.1. Mathematical Measures of Reliability. Reliability is basically the probability of the device performing properly under typical operating conditions for the expected lifetime intended. The classical statistics along with system reliability approaches using series and parallel system of " $n$ " components and modern high performance computing (HPC) have provided ways to measure reliability of MEMS. These are equally supported by experimental analysis, theoretical and mathematical modeling, and simulations. These approaches effectively measure the reliability function, failure rates, mean time to failure, and so forth [62]. Consider the following:

$$
R(t)=1-F(t) .
$$

$R(t)$ is the reliability (survival) function which is the probability of operation without failure to time $t . F(t)$ is the cumulative failure function (CDF) and is the probability that a randomly chosen part will fail at time $t . f(t)$ is the lifetime distribution model that serves as the probability density function (PDF) over the time range from 0 to $\infty$. CDF and PDF can be correlated as [20]

$$
\begin{gathered}
F(t)=\int_{0}^{t} f\left(t^{\prime}\right) d t^{\prime}, \\
f(t)=\frac{d}{d t} F(t) .
\end{gathered}
$$

2.2. Reliability Distribution. The distribution of the failure over the lifetime of the device population is significantly essential to MEMS reliability. With the help of these distributions, the functions can be developed and used for predictive purposes $[20,63]$. Another important property of probability is the hazard or the instantaneous failure rate denoted by $h(t)$. It is the ratio of the failure in the next time interval and the reliability $R(t)$ of the device [64]. Consider the following:

$$
h(t)=\frac{f(t)}{R(t)}=\frac{f(t)}{1-F(t)}
$$

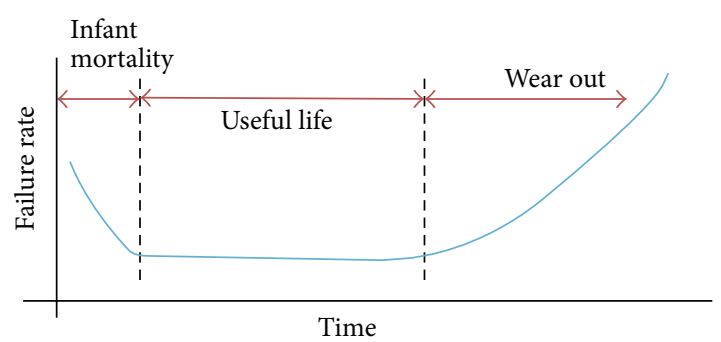

Figure 2: Bathtub curve [54].

or

$$
h(t)=-\frac{1}{R(t)} \frac{d R(t)}{d t}
$$

or

$$
h(t)=-\frac{d}{d t} \ln R(t)
$$

The integral of the hazard rate is the cumulative failure rate and is given by

$$
H(t)=\int_{0}^{t} h\left(t^{\prime}\right) d t=-\ln R(t) .
$$

An essential reliability factor is how long a certain population will survive without failure? This phenomenon is called mean time to failure (MTTF) and is given by the following equation showing the first mean time to failure [65]:

$$
\operatorname{MTTF}=t^{\prime} \equiv \int_{0}^{\infty} t f(t) d t
$$

With the help of these statistical distributions, the device lifetime can be predicted under its expected operating conditions. Some of the most common statistical distributions are listed below:

(1) bathtub curve,

(2) exponential distribution,

(3) weibull distribution,

(4) lognormal distributions.

2.2.1. Bathtub Curve. The failure rate of MEMS that changes over the lifetime of the device, starting high, reducing and increasing towards the end of the device's life, is named bathtub curve and is shown in Figure 2.

This bathtub curve shows the three stages over the MEMS lifetime: the high initial failure due to infant mortality, constant failure rate over the useful lifetime, and increased failure rate as the device ages [58]. The reliability at these points depends on the competence of MEMS devices to survive degradation that arises during the operation capturing the whole lifetime of these devices [24]. The bathtub curve is a good tool when there is a single population under consideration; however, in the case of multiple populations, the subsequent statistical analysis can be incorporated. 
2.2.2. Exponential Distribution. The exponential distribution is the most simplest as compared to all lifetime distribution models, where the failure rate or hazard rate $h(t)$ is denoted by $\lambda$ and is treated as a constant. It is appropriate for the constant failure rate region in the bathtub curve. In the exponential distribution, the reliability, the cumulative distribution function, and the probability distribution function are given as [20]

$$
\begin{gathered}
R(t)=e^{-\lambda t} \\
F(t)=1-e^{-\lambda t} \\
f(t)=\lambda e^{-\lambda t}
\end{gathered}
$$

The mean time to failure of the exponential function is the inverse of failure rate $\lambda$. Consider the following:

$$
\operatorname{MTTF}=\frac{1}{\lambda} .
$$

2.2.3. The Weibull Distribution. It is used to fit a variety of shapes of reliability curves and can be expressed in multiple ways. The Weilbull distribution is basically the probability of survival between time zero and time $t[66,67]$. Consider the following:

$$
R(t)=e^{-(1 / \alpha)^{\beta}} \Longrightarrow \frac{f(t)}{h(t)},
$$

when $\beta=1$, the above equation becomes the exponential model (bathtub reliability equation); when $\alpha=1 / \lambda$ it becomes the MTTF equation. Two-parameter fit models are commonly used in reliability lifetime prediction. The probability density function of the two-parameter Weilbull's model is given by

$$
f(t)=\frac{\beta}{t}\left(\frac{t}{\alpha}\right)^{\beta} e^{-(t / \alpha)^{\beta}} .
$$

2.2.4. Lognormal Distribution. It is a continuous probability distribution of random variables whose $\log$ is normally distributed and can model a random variable $x$, where $\log (x)$ is normally distributed. Lognormal time to failure is named a $\log$ normally distributed. The probability distribution function in time unit of $T_{50}$ is given by the following equations:

$$
\begin{gathered}
f(t)=\frac{1}{\sigma t \sqrt{2 \pi}} e^{\left(-\left(\ln (t)-\ln \left(T_{50}\right)\right)^{2} / 2 \sigma^{2}\right)}, \\
F(t) \int_{0}^{T} \frac{1}{\sigma t \sqrt{2 \pi}} e^{\left(-\left(\ln (t)-\ln \left(T_{50}\right)\right)^{2} / 2 \sigma^{2}\right)} d t .
\end{gathered}
$$

\section{MEMS Failure Mechanism}

Unlike ICs, MEMS devices move and thus special tools and techniques are required to measure the mechanical motion on a nanometer scale in all 6 degrees of freedom. These tools are used to understand the device's behavior in detail so as to provide feedback to the designer in order to improve the

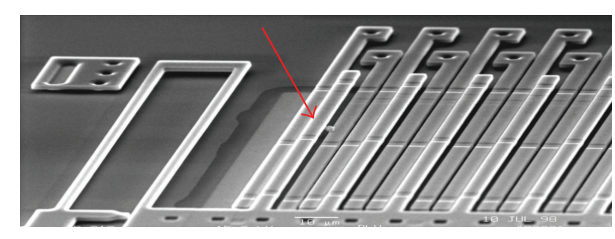

Figure 3: Particle obstruction in inertial sensor (Courtesy Sandia National Laboratories).

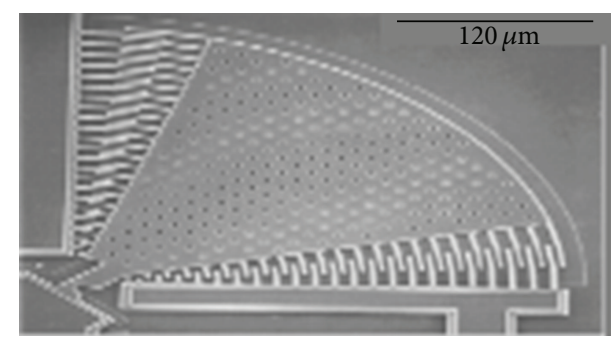

FIGURE 4: Electrostatically driven polysilicon MEMS comb fingers with a notch at the anchor (Courtesy Sandia National Laboratories).

reliability in the design. The reliability tool kit has to measure minute changes in the device's behavior after accelerated testing (large number of cycles, mechanical shock, thermal cycling, and so forth) to estimate the lifetime once the failure mechanism has been identified.

Several kinds of MEMS devices are used in a range of applications across the globe. MEMS devices were once thought to be in the family of ICs and may carry the same failure mechanism as the ICs. However, due to the unique structure and geometry of MEMS devices, and its various biasing techniques, the failure mechanism of these devices is categorized based on the complexity of the MEMS devices. MEMS devices are divided into the following four groups.

Group 1 contains MEMS devices with no moving parts, such as DNA sequencers, microphones, and chemical sensors. Particle contamination stimulates failure in this group of MEMS devices. In fact, particles tend to mechanically obstruct the operation of MEMS devices. Due to their small size and being nonelectrical in nature, it is difficult to detect particle contamination as it will not electrically bridge the structure that can result in short circuits. A typical example of particle contamination is shown in Figure 3. Here the sensor cannot move and hence cannot create an output signal to be forwarded to the readout circuitry [53].

Group 2 consists of MEMS devices with some moving parts and no rubbing surfaces, such as accelerometers, gyroscopes, and comb drives. Reports have suggested that hinges and microcantilever yoke regions are prone to fatigue as shown in Figure 4. To study the structural failure (fatigue) in this group, electrostatically actuated comb fingers with a perforated proof mass and a microcantilever with a notch is presented. Stress levels at the notch initializes cracks on the surface of the microcantilever that tend to reduce the life of the device and ultimately causes the failure of the device by fracture [18]. 


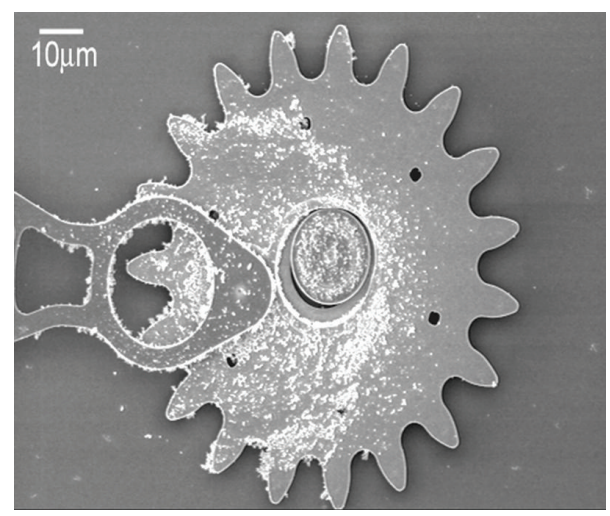

FIGURE 5: Wear debris on the surface of the microengine (Courtesy Sandia National Laboratories).

Group 3 includes MEMS devices having moving parts with impact surfaces, such as thermal actuators, valves, and relays. These devices are susceptible to debris created on the surfaces, fracture components, cracks, and so forth. Failure in the MEMS structure occurs due to a fracture as a result of impacting forces on the opposite structure of the MEMS devices [18].

Group 4 represents MEMS devices with moving, impacting, and rubbing surfaces, for example, optical shutter, micromirror, geared devices, and so forth. Moving components create friction that results in wear material or debris causing several failures, such as (1) failure by particle contamination, (2) particles creating third body wear that changes the motion tolerance, and (3) adhesion of rubbing or contacting surfaces. These characteristics can be seen in Figure 5 [68]. It is noticeable that particle contamination and stiction can cause failure in all kinds of MEMS devices. It is, therefore, emphasized that the root causes of failure must be known before jumping for remedies of the particular failure.

MEMS sensors and actuators by their classifications into groups and by their nature have different and unique failure mechanisms. In ICs, electrical parameters are measured to tackle the failure, whereas in MEMS both the electrical and mechanical parameters are endorsed to deal with the failure and to enhance reliability [51]. Further details can be seen in Table 1, which summarizes the MEMS common causes of failures and its procurement.

\section{Mechanical Failure in MEMS}

MEMS components consist of beams or membranes that are flexible or rigid, one- or two-sided clamped, with or without perforation on its surface. It also contains conductive or insulative flat layers, hinges, cavities, and gears connected to an electronic readout circuit [13]. On the other hand, traditional MEMS devices, such as pressure sensors and cantilevers, have been integrated into accelerometers, contact switches, micromirrors, micropumps, valves, and so forth. MEMS structures, once moving along a single axis, have been replaced by multiaxes moments. Structures and applications of MEMS devices are becoming more complex. In order to improve the performances of MEMS devices, it is essential to know at the very preliminary stage the fundamental causes of their failures. These failure analyses can greatly help in understanding the root causes of failures at the wafer level to the final packaging of the device [77]. The device intercommunication and compatibility to perform its desired functions result in certain failure mechanisms. Table 2 lists some of the major mechanical failures of MEMS devices.

The rapid market growth of MEMS products is evidence of the improved reliability of MEMS devices. No doubt, poorly designed MEMS devices can carry multiple modes of failures; circumspectly designed MEMS products can congregate the harsh reliability provision of MEMS applications. It is a general perception that most of the failures of MEMS devices are related to their mechanical portions; however, electrical reliability issues have been unnoticed over and over again. These are responsible for a high electric field applied across the dielectric of MEMS devices. Some important electrical reliability issues that cause electrical failures in MEMS devices are listed in Table 3 [78].

MEMS devices work on the principle of mechanical vibrations that generate an output from the device. The generated output can never be the same due to the various MEMS structures that rely on the dynamic displacements and variations in the stress levels, hence resulting in an output error, enough to disturb the sensitivity of the device [79]. Sensitivity is the ratio of the magnitude of the output signal to the input stimuli. Sensitivity is an important factor in device selection [80, 81]. The sensitivity, power consumption, and frequency ranges of MEMS sensors and actuators used in medical, automobile, defense, communication and seismology are listed in Table 4.

\section{Fatigue in MEMS}

Fatigue plays a major role in making the MEMS devices unreliable. Since 1992, after being discovered, it has been widely studied and observed by many researchers and academicians. Each MEMS device has unique configurations; therefore, it carries unique fatigue occurrences, which by any means are different from device to device [84].

Fatigue is the localized and structural damage that occurs when a material is subjected to cyclic loading. It starts with a crack that starts at an area of high stress and slowly propagates through the material until there is a failure of the device. This is limited to the active components of MEMS devices, that is, cantilevers, membranes, and comb drives [38]. However, passive structures are not physically exposed to mechanical stress cycles enough to stimulate fatigue. Formation of cracks on the structures initiates fatigue which gradually spreads up through the material until there is a catastrophic failure of the device $[17,85]$. Several changes on the surface of MEMS devices have been observed during cyclic stress actuations and interactions of water molecules with the silicon dioxide layer. It has also been reported that no fatigue was observed in silicon when cyclic loading was $50 \%$ less than the total silicon fracture strength $[86,87]$.

Initially researchers have emphasized on high frequencies for prediction of the fatigue lifetime of polysilicon MEMS 
TABLE 1: Summarizes various MEMS groups, their causes of failure, and procurement of the failures.

\begin{tabular}{|c|c|c|c|}
\hline Group & $\begin{array}{l}\text { Causes of failure/reliability } \\
\text { issues }\end{array}$ & Test & Reference \\
\hline \multicolumn{4}{|l|}{ Group 1} \\
\hline $\begin{array}{l}\text { DNA sequencers } \\
\text { Microfludic } \\
\text { nozzles } \\
\text { Chemical sensor }\end{array}$ & Dielectric breakdown & $\begin{array}{l}2 \times 4 \text { microfludic array, } \mathrm{X} \text { and Y direction } \\
\text { electrodes were shorted, respectively; the effects of } \\
\text { changes on the electrodes were simulated, and } \\
\text { transportation of droplets was observed by CCD } \\
\text { Camera. }\end{array}$ & [69] \\
\hline
\end{tabular}

Group 1 or 2 Mechanical wear, fracture,
fatigue, charging, change in
friction
(1) Built in self repairable tests within the device were reported. Comparison of BISR and Non-BISR MEMS; simulation of fatigue and S-N (no. of cycles to failure) curve

(2) Accelerated life time experimental tests were performed for 1000 hours at about $145^{\circ}$ to $200^{\circ} \mathrm{C}$.

(3) Fatigue testing using Tytron 250. The experimental fatigue life lines were between $7.78 \times 10^{4}$ to $1.48 \times 10^{7}$ cycles at the stress levels of 2.05 to $2.83 \mathrm{GPa}$.

(4) Sandia National Laboratories have developed the Sandia High volume Measurement of Micromachine Reliability (SHiMMeR) to control and measure up to 256 MEMS parts, simultaneously; it is a Plexiglas enclosure with a high power optical microscope and cameras.

(5) Military Test Standard Device

(MIL-STD-883F) for stiction, Diamond Like

Carbon (DLC coating) for wear, X-rays diffraction

for fatigue and creep, and for contamination Scanning acoustic Microscope (SAM)

Group 2

Pressure sensors

Fracture, fatigue, shock, vibrations, and change in friction

Sensors were designed and manufactured well below the stress level where fatigue was detected in silicon; fatigue in pressure sensor occurred when stress and fracture levels were almost equal.

(1) Adhesion failure mode in lateral capacitive gyroscope was experimentally analyzed.

(2) Variations in noise and signal out as well as temperature degradations were reported.

Group 3 vibrations

(1) Fracture experimental tests were performed by applying load on the beam using Weibull statistics. (2) Experimental methodology for the evaluation of creep in microswitches based on the

Thermal actuator

Mechanical wear, shock, and vibrations

deformation of the switch due to charging and due to creep.

(3) Pull-in voltages were observed in bend and torsinol modes. fatigue tests were carried out and the predicted life time reported was $10^{11}$ cycles.

(1) Design issues were classified; more research is needed for better understanding.

(2) Fatigue test of thick aluminum specimen was observed in liquid environment.

$10^{9} \mathrm{on} / \mathrm{off}$ switching cycles without stiction and welding induced failure were reported.
Mechanical wear, fracture, fatigue, shock, and vibrations

Mechanical wear, fracture, fatigue, shock, vibrations, and charging
Micro relays 
TABle 1: Continued.

\begin{tabular}{|c|c|c|c|}
\hline Group & $\begin{array}{l}\text { Causes of failure/reliability } \\
\text { issues }\end{array}$ & Test & Reference \\
\hline \multicolumn{4}{|l|}{ Group 4} \\
\hline Electrostatic actuator & $\begin{array}{l}\text { Mechanical wear, fracture, } \\
\text { fatigue, shock, vibrations, } \\
\text { and charge in friction }\end{array}$ & $\begin{array}{l}\text { Analysis of pull-in and pull-out voltages using } \\
\text { stochastic modeling for prediction of life time of } \\
\text { devices }\end{array}$ & {$[39,74,75]$} \\
\hline Optical shutter & $\begin{array}{c}\text { Mechanical wear, fracture, } \\
\text { fatigue, shock, and } \\
\text { vibrations }\end{array}$ & Imprecise data availability & \\
\hline Mirror device & $\begin{array}{l}\text { Mechanical wear, fracture, } \\
\text { fatigue, shock, vibrations, } \\
\text { and optical degradation }\end{array}$ & $\begin{array}{l}\text { Texas Instruments (TI) developed the } \\
\text { MirrorMaster, a custom optical inspection tool for } \\
\text { DMD devices that inspects every pixel of the } \\
\text { DMD array and determines the response of each } \\
\text { pixel to different electrical drive signals. }\end{array}$ & [7] \\
\hline Gear devices & $\begin{array}{l}\text { Mechanical wear, fracture, } \\
\text { fatigue, shock, vibrations, } \\
\text { and charge in friction }\end{array}$ & $\begin{array}{l}\text { Simulations of sliding surfaces prevented } \\
\text { adhesion and wear }\end{array}$ & {$[76]$} \\
\hline Microturbine/fan & $\begin{array}{l}\text { Mechanical wear, shock, } \\
\text { vibrations, and charge in } \\
\text { friction }\end{array}$ & Imprecise data availability & \\
\hline
\end{tabular}

TABLE 2: Mechanical failures.

\begin{tabular}{|c|c|c|c|c|c|}
\hline \multicolumn{6}{|c|}{ Mechanical fracture } \\
\hline Failure & Overload & Shock & Corrosion & Fatigue & \\
\hline Causes & Excessive stress & $\begin{array}{c}\text { Drops, excessive } \\
\text { loading, and } \\
\text { mechanical } \\
\text { interference disorder }\end{array}$ & $\begin{array}{c}\text { Chemical reaction, } \\
\text { oxidation }\end{array}$ & $\begin{array}{l}\text { Structural damage at } \\
\text { cyclic loading }\end{array}$ & \\
\hline \multicolumn{6}{|c|}{ Stiction } \\
\hline Failure & Vander Waals forces & Capillary forces & Chemical bonding & Electrostatic charging & Residual stress \\
\hline Causes & $\begin{array}{l}\text { Interaction of atoms } \\
\text { or molecules at the } \\
\text { surface of close } \\
\text { contact }\end{array}$ & $\begin{array}{c}\text { Monolayer of water } \\
\text { on all surfaces that } \\
\text { lubricates the surface } \\
\text { inducing capillary } \\
\text { force }\end{array}$ & $\begin{array}{c}\text { Chemical bond } \\
\text { between contacting } \\
\text { surfaces }\end{array}$ & $\begin{array}{c}\text { Two closed surfaces at } \\
\text { different potentials }\end{array}$ & $\begin{array}{c}\text { During the release } \\
\text { process structure } \\
\text { tends to bend or } \\
\text { deform }\end{array}$ \\
\hline \multicolumn{6}{|c|}{ Wear } \\
\hline Failure & Adhesion & Abrasion & Corrosion & Surface fatigue & \\
\hline Causes & $\begin{array}{l}\text { Pulling off fragments } \\
\text { of another surface } \\
\text { while sliding due to } \\
\text { surface forces } \\
\text { between them }\end{array}$ & $\begin{array}{c}\text { Stripping away } \\
\text { material from soft } \\
\text { surface while sliding } \\
\text { of harder surface }\end{array}$ & $\begin{array}{l}\text { When two surfaces } \\
\text { chemically interact }\end{array}$ & $\begin{array}{l}\text { Smooth surfaces are } \\
\text { subjected to cyclic } \\
\text { loading instead of } \\
\text { sliding }\end{array}$ & \\
\hline \multicolumn{6}{|c|}{ Creep and fatigue } \\
\hline Failure & Intrinsic stress & Applied stress & Thermal stress & & \\
\hline Causes & Residual stress & Input load & Overheating & & \\
\hline
\end{tabular}

TABLE 3: Electrical failures.

\begin{tabular}{|c|c|c|c|c|}
\hline \multicolumn{5}{|c|}{ Electric short and open circuit } \\
\hline Failure & Dielectric material degradation & ESD, high electric field & Electromigration & Oxidation \\
\hline Causes & Capacitive discharges & excessive load & Mismatch load & Environmental \\
\hline \multicolumn{5}{|c|}{ Contamination } \\
\hline Failure & Intrinsic (crystal growth) & Manufacturing-induced & Usage environment & \\
\hline Causes & Environmental & Rough handling in industry & Low, high temperature and humidity & \\
\hline
\end{tabular}


TABLE 4: The sensitivity of various MEMS devices [82, 83].

\begin{tabular}{|c|c|c|c|}
\hline $\begin{array}{l}\text { Fields of } \\
\text { application }\end{array}$ & $\begin{array}{l}\text { Sensitivity in } \\
\text { value "g" }\end{array}$ & $\begin{array}{c}\text { Power } \\
\text { consumption }\end{array}$ & $\begin{array}{l}\text { Frequency } \\
\text { range } \\
\end{array}$ \\
\hline Medical & \pm 16 & $\geq 19 \mathrm{~mA}$ & $\begin{array}{c}2.4 \\
\mathrm{MHz} \text { IEEE }\end{array}$ \\
\hline Implantable & $\pm 2, \pm 4, \pm 8, \pm 16$ & $25 \mathrm{uA}$ & 2.4 MH IEEE \\
\hline Automobile & $\pm 35, \pm 50, \pm 70$ & $\geq 1.3 \mathrm{~mA}$ & $2.50 \mathrm{GHz}$ \\
\hline Defense & $\mathrm{Up} \pm 70$ & $2.0 \mathrm{~A}, 20 \mathrm{~V}$ & $\begin{array}{l}650 \mathrm{KHz} \text { to } \\
1.5 \mathrm{MHz}\end{array}$ \\
\hline Communication & \pm 20 to \pm 70 & $\begin{array}{l}\text { Fluctuates with } \\
\text { applications }\end{array}$ & 2.7 to $10 \mathrm{GHz}$ \\
\hline Seismology & $\geq \pm 2$ & $\begin{array}{l}\text { Fluctuates with } \\
\text { applications }\end{array}$ & $\geq 1 \mathrm{KHz}$ \\
\hline
\end{tabular}

devices in the bend state [88-90]. Not only testing the fatigue lifetime of polysilicon at lower frequencies is time consuming, but also the mechanical loading has been confined to high frequencies only [91]. There is a long list of tests and experimental procedures for predicting the fatigue lifetime using numerous approaches. However, there is no enough evidence of merging the existing experimental data in correlation to drawing a mathematical model for the prediction of the fatigue life cycle of MEMS. References [92] reported a modeling approach for the prediction of the fatigue lifetime of polysilicon by taking the variations in the thickness and creating a multiparameter expression for the prediction of the fatigue lifetime of polysilicon. The MEMS structure was subjected to various variations in the design rules. This revealed that the devices' physical shapes (geometry) play an important role in changing the devices' performances.

In the failure analysis, the process wreckage or debris is sometimes not possible to examine using an optical microscope or SEM due to the fact that the rubbing surface rests below the other structure. It is, therefore, recommended that the focused ion beam (FIB) is used for a clean observation of the cross-sectional area of the MEMS structures $[93,94]$.

Many researchers have investigated the behavior of fatigue in MEMS; unfortunately, there are no reputable methods on the basis of which the fatigue behavior can be explained for many uncertain factors which leads to the ultimate failure of the MEMS device [72]. Fatigue crack initialization can be seen in Figure 6.

In general, the fatigue process involves (1) crack nucleation, (2) short crack growth, (3) long crack growth, and (4) final fracture. Cracks start at the localized shear plane at or near high stress concentrations, such as persistent slip bands, inclusions, porosity, or discontinuities. Crack nucleation is the first step in the fatigue process. Once nucleation occurs and cyclic loading continues, cracks tend to grow along the plane of the maximum shear stress and through the boundary of the component [95].

5.1. Crack Growth Model for Fatigue Analysis. The crack growth model [41] that is used to describe fatigue is given as

$$
K_{I}=\sigma Y c^{1 / 2}
$$

where $K_{I}$ is the measure of intensity, $\sigma$ is the applied stress, $Y$ is the crack shaped parameter, and $c$ is the crack length. Failure will occur when $K_{I}$ exceeds a critical value, $K_{\mathrm{IC}}$, the intrinsic strength of the material is exceeded, and catastrophic failure occurs.

A power law relationship between the crack growth rate/velocity, $\dot{c}$, and the applied stress at the crack tip [41, 42 , $96,97]$ is given as

$$
\frac{d c}{d t}=\dot{c}=A\left(\frac{K_{I}}{K_{\mathrm{IC}}}\right)^{n} .
$$

This form of relation is mathematically convenient since static and dynamic fatigue equations can be found in an analytically closed form and it is mathematically compatible with the Weilbull distribution, commonly used to describe the statistical variability in strength; however, it is not based on any physical model. $A$ is a preexponential term, which represents the overall crack growth, depending on the environments, and $n$ is the fatigue parameters (represents how sensitive the rate is to the applied stress) [43]. A can be described by an Arrhenius dependence on temperature. The applied stress causes the crack to extend, which itself increases $K_{I}$, leading to an increase in the growth rate (13). Eventually, $K_{I}$ reaches $K_{\text {IC }}$ and failure occurs. To determine the time to failure, (13) and (14) can be utilized for given input parameters. In most reliability models, the applied stress is assumed to be static ( $\sigma_{a}=$ constant $)$ so that the time to failure, $t_{f}$, is given by [45]

$$
t_{f}=\frac{2}{A Y^{2}(n-2) \sigma_{a}^{n}}\left(\frac{\sigma_{i}}{K_{\mathrm{IC}}}\right)^{n-2},
$$

where $\sigma_{i}$ is the initial strength of the material in the absence of the fatigue and can be referred to as the initial crack length, $c_{i}$, by (13)

$$
K_{\mathrm{IC} i}=\sigma_{i} Y c_{i}^{1 / 2} .
$$

Equation (15) is derived using the approximation that the initial crack size, $c_{i}$, will be much smaller than the final crack length, $c_{f}$, when unstable crack growth occurs:

$$
K_{\mathrm{IC} f}=\sigma_{a} Y c_{f}^{1 / 2} .
$$

5.2. Paris' Law for Fatigue Crack Growth. This law deals with the stress intensity in association with the subcritical crack growth under a fatigue stressed area. It is the commonly used fatigue crack growth model in material science; its basic formula corresponds with

$$
\frac{d a}{d N}=c \Delta K^{m},
$$

where $a$ corresponds to the crack length and $N$ represents the number of load cycles. $d a / d N$ is the crack growth rate, in other words, the crack growth per increasing number of load cycles, $c$ and $m$ are the material constants, and $\Delta K$ is the range of the stress intensity factors, which can be stated as the difference between the stress intensity factors at the 


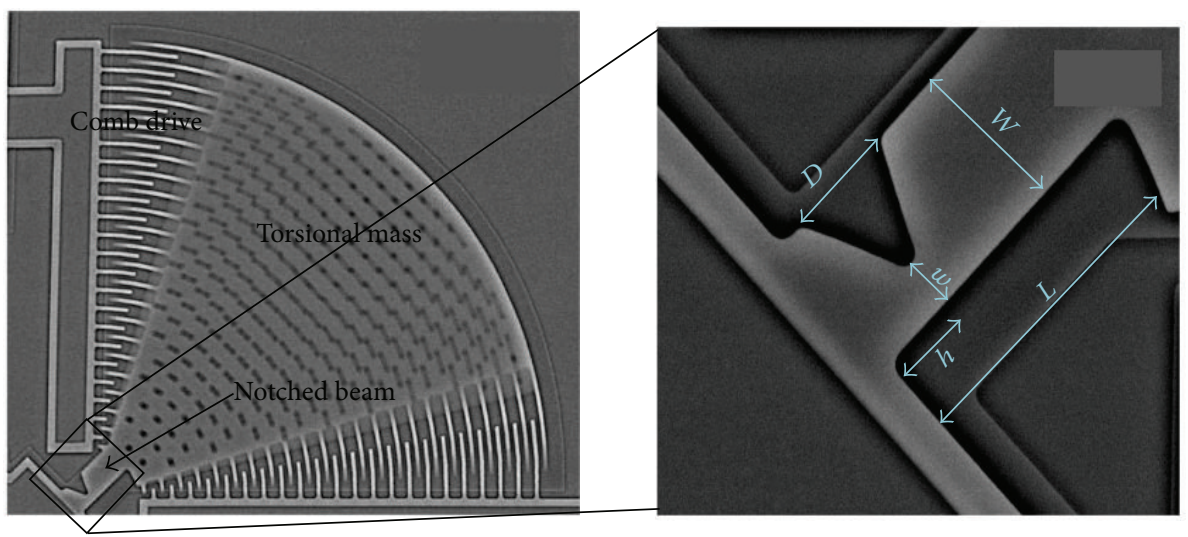

FIGURE 6: SEM of the polysilicon fatigue characterization with details of notched cantilever [38].

maximum and minimum loading. It can be written as $\Delta K=$ $K_{\max }-K_{\min }$. Consider the following:

$$
K=\sigma Y \sqrt{\pi a}
$$

where $\sigma$ is the uniform tensile stress perpendicular to the crack plan and $Y$ is the dimensionless parameter that depends on the geometry. The range of the stress intensity factors can be given as

$$
\Delta K=\Delta \sigma Y \sqrt{\pi a}
$$

where $\Delta \sigma$ is the range of the cycle stress amplitude and $Y$ takes the value 1 for a center crack in an infinite sheet. Consider the following:

$$
\begin{gathered}
\frac{d a}{d N}=c \Delta K^{m} \Longrightarrow c(\Delta Y \sigma \sqrt{\pi a})^{m} \\
\int_{0}^{N f} d N=\int_{q i}^{a c} \frac{d a}{c(\Delta \sigma Y \sqrt{\pi a})^{m}} \Longrightarrow \frac{1}{c(\Delta \sigma Y \sqrt{\pi})^{m}} \int_{a i}^{a c} a^{-m / 2} d a \\
N_{f}=\frac{2\left(a c^{(2-m) / 2}-a i^{(2-m) / 2}\right)}{(2-m) c(\Delta \sigma Y \sqrt{\pi})^{m}} .
\end{gathered}
$$

$N_{f}$ is the remaining number of cycles to fracture, $a c$ is the critical crack length at which instantaneous failure will occur, and $a i$ is the initial crack length at the fatigue growth that starts for a given stress range $\Delta \sigma[98,99]$.

\section{Effects of Humidity and Temperature on the Reliability of MEMS}

Single crystal silicon and polycrystalline silicon are the two major structural materials of MEMS devices. The electrical properties of these materials are well established; however, their mechanical properties in analyzing the fatigue for the prediction of the lifetime of a MEMS device is still not well understood. Consequently, the fatigue lives of silicon and polysilicon by means of its reliance on the applied stresses under various environmental effects have been explored [100-102].

Silicon was deemed to be a perfect brittle and fatigue free material at room temperature [103]. However, many researchers have declared that single crystal silicon and polysilicon undergoe mechanical fractures due to the fatigue growth rate and cyclic stresses exposed to a range of temperature and humid environments [104-106].

Humidity plays a major role in the performances of the MEMS devices, particularly on the active components. The fatigue test on humidity has been presented by [107], at various stress levels and at a fixed 50\% relative humidity (RH) on polysilicon thin films. This study has presented that the fatigue life was found to be $10^{6}$ to $10^{11}$ cycles. Also, the fatigue damage accumulation is linked with the various levels of humidity and its respective changes in the resonance frequencies of devices under observation.

The effects of humidity on the surface of the polysilicon thin films revealed that surface oxide layers endure a subcritical and environmentally assisted crack; alternatively thick oxide layers are responsible for the crack formation or nucleation [108, 109]. However, fatigue behavior is typically an outcome of subcritical cracking on the surface roughness of MEMS devices [110].

An unorthodox approach in evaluating the fatigue of the polycrystalline silicon membrane and its dependence on humidity was adopted in [111]. In this setup, a circular weight of $12 \mathrm{~mm}$ in diameter was placed at the center of the membrane to control the resonance frequency; stress was generated by deforming the membrane, oscillating the weight in and out of the plane direction. The fatigue damage growth was observed by increasing the stress on the membrane. The fatigue damage rate was low at a lower humidity and increased with an increase in the level of humidity.

The correlated effect of the temperature and humidity on a microfabricated MEMS structure is not known and has been the interest of this study. However, it is a wellaccepted fact that the fatigue of a bulk material is highly dependent on the temperature and humidity. It has been shown that the activity 
at the crack tip is proportional to the relative humidity in the ambient environment [42]. The expected relationship between the crack growth, $A$, and the temperature $T$ and humidity $R H$ can be given as

$$
A=v f(R H) \exp \left(-\frac{Q}{R T}\right) .
$$

In the above expression, the reaction rate constant is assumed to have an apparent activation energy, $Q$, and some functional dependence on the humidity activity, $f_{I}(R H)$; $v$ is a frequency factor. $T$ is the absolute temperature and $R$ is the gas constant.

Over the last two decades, the silicon-based MEMS devices brought a revolution in the field of micro/nanoelectromechanical systems. However, there is a great need to focus on the reliability of these devices, both at the structural (geometry) and design levels. Environmental effects on the silicon thin film at room temperature were evaluated by [112]. Their study has demonstrated how an environmental effect can propagate fatigue in thin film through oxidation by evaluating the nanometer scale surface oxide layers. The tensile stress test for the single crystal silicon (SCS) thin film was carried out in a humid environment by [113]. Fatigue lifetime long term prediction was performed by Weibull's statistics using the maximum likelihood method; humidity effects were observed on the scale parameter which decreased the strength of the thin film affecting its long term reliability. However, no fatigue was observed in the vacuum.

A polycrystalline silicon thin film structure was observed for fatigue analysis at room temperature in ambient air and at a compressional loading of about $40 \mathrm{KHz}$. The transmission electron microscopy (TEM) of the surface test sample showed the gradual thickening of the surface oxide layers that increased fatigue failure concentrations. Interesting observations in the fatigue mechanism were recorded. The results showed that moisture assisted the subcritical cracking within a cyclic stress. An assisted thickened layer occurred until the crack reached a critical size to cause a sudden failure of the entire device. The reaction layer fatigue mechanism is the leading mechanism for fatigue failure in microscale polycrystalline silicon thin film [106]. Reliability also depends on the quality and strength of the material used as reported in [114]. They conducted a thorough study and suggested that silicon and polysilicon have the essential mechanical robustness for microelectromechanical applications. However no such study was reported about the fatigue lifetime in low and high temperatures operating in humid environments.

Tensile and bending tests for the fatigue lifetime of polysilicon have been regularly used by researchers. Such investigations were carried out in [33] for determination of the fracture strength and fatigue lifetime of polysilicon. The sample was examined under the influence of a $1 \mathrm{~Hz}$ cyclic tensile frequency and showed that with the decrease in the fracture stress increases the lifetime of the sample. The fatigue lifetime of polysilicon was tested by $[115,116]$ with a frequency ranging from $50 \mathrm{~Hz}$ to $6 \mathrm{KHz}$. Their observations concluded that the decrease in the fracture strength resulted in an increase in the fatigue lifetime of polysilicon; however, no frequency drift was observed during the process.
A piezoelectric actuator was used by [117] for the investigation of the tensile testing of the structure of a Polysilicon thin film. Their mechanical arrangement consists of a stationary outer frame and a movable inner frame that were connected in parallel through a spring. The gap between the two frames was carefully filled by the structure of the polysilicon. The fatigue lifetime and fracture strength were achieved when the movable inner frame was exposed to an external loading.

The beam bending phenomena for the prediction of the fatigue lifetime has been demonstrated by [118] with the use of an electrostatic comb drive as a notch sample at the frequency of $20 \mathrm{KHz}$. Observations showed that low stress resulted in an increase in the fatigue lifetime of the material. The fatigue lifetime of polysilicon was studied and reported in [119] under high frequency $(\sim 40 \mathrm{KHz})$. The experimental setup contained a sample notch cantilever beam attached to a perforated plate serving as a resonant mass. The outcome of their research showed that reducing the stress at the root of the notch will result in a prolonged fatigue life.

A microcantilever beam with an electrostatic load was used for the prediction of the fatigue lifetime of polysilicon [84]. The mechanical arrangements consisted of a copper plate with two pads, a microcantilever, and the sample. With the applications of the voltage across the sample, an electrostatic load was produced resulting in a bend in the beam. Fatigue was determined by the point where the pad wedged with the copper plate and did not return to its original position. The automatic testing machine (MTS Tytron 250) was used for the study of the fatigue lifetime of the polysilicon microcantilever in the bend state. The fatigue life cycles calculated were $9.1 \times 10^{5}$ and $1.53 \times 10^{7}$ cycles with stresses of 2.37 to $3.7 \mathrm{Gpa}$ at room temperature. It was documented that high stresses reduced fatigue life [91]. A similar study has been reported for fatigue testing in a micromirror using MTS Tytron 250 microforce system. The experimental fatigue life cycle was between $7.78 \times 10^{4}$ and $1.48 \times 10^{7}$ cycles at the stress level of 2.05 to $2.83 \mathrm{GPa}$ [34].

A study of the fatigue of polysilicon in the bend position [88] demonstrated, with the help of an electrostatic comb structure, beam, and movable masses, that, with the supplied voltages, the movable masses oscillated and tended to bend the beam. The fatigue fracture was calculated at the cyclic loading stress of $3 \mathrm{Gpa}$.

An on-chip test structure was developed by $[120,121]$ for the fatigue analysis; the experimental arrangements contained an electrostatically driven actuator, sensor, movable mass (responsible of delivering force to the notched beam), and a notched beam. It was demonstrated that large stress reduces the fatigue life cycle. High humidity will affect the fatigue life cycle of polysilicon thin film in harsh environments as reported by [122]. Effects of frequency on the fatigue lifetime were experimentally demonstrated with the help of an atomic force microscope, nanoindentation, and tensile tester. They demonstrated that the sample size and deformation mode can affect the fatigue lifetime. References $[123,124]$ reported the fatigue lifetime of single crystal 
silicon in bending. The experimental analysis showed that the frequency altered the damage growth rate, and hence, the lower frequencies were held responsible for reducing the fatigue lifetime of single crystal silicon.

A detailed study of the fatigue lifetime of polysilicon in the bend state has been reported [125]. A piezoelectric microcantilever was actuated on $100 \mathrm{~Hz}$. It was observed that the applied stresses were inversely proportional to the fatigue lifetime of polysilicon in the bend state. They have utilized the effects of frequency on the fatigue lifetime; however, they remained quiet on the effects of the fatigue lifetime of MEMS device operation in low and high temperatures and a humid environment.

The effects of humidity and temperature on the fatigue of polysilicon thin film were tested and reported by [126]. They observed the fatigue behavior of polysilicon thin film in air, relative humidity of $80 \%$ at $22^{\circ} \mathrm{C}$, and using inert nitrogen gas at $22^{\circ} \mathrm{C}$ and $180^{\circ} \mathrm{C}$, respectively. Various stress amplitudes in association with the number of fatigue cycles were combined using the statistical analysis; Paris' law was incorporated in order to observe the fatigue crack extension. The outcome of this research suggested that fatigue damage is due to repeated loading even in inert environments; they further reported that high temperatures increase the fatigue damage rates.

In reference with the literature, it has been found that the fatigue behavior, a major reliability issue, has not been observed at the point of clarity at high and low temperatures. The fatigue analysis of the MEMS under the impact of humidity and frequency requires some attention. Another important point of observation is that the correlation between the temperature, humidity, and frequency in the fatigue analysis has not yet been observed. Standard reliability test methods and approaches are much needed in order to bridge the failure mechanism of MEMS devices. Root causes of failure of reliability in MEMS are extremely product dependent. Sufficient technical data has not been available on the basis of which specific and general failure mechanisms of MEMS devices can be targeted.

\section{Summary}

It is a fact that the MEMS market is gaining momentum. Reliability of MEMS devices is a well known upcoming challenge for academia and industry. It is viable to understand the failure mechanism of MEMS devices. One of the obvious factors affecting the reliability of MEMS devices is fatigue. Based on the complex nature of MEMS devices, an in-depth understanding of the reliability both at the technological and environmental operational levels is essential. This study reviewed the reliability issues that have been reported in MEMS devices and mathematically measured the reliability in order to predict the lifetime of MEMS devices under testing. The various MEMS groups, causes of failure, and the procurement of the failures were discussed.

MEMS mechanical failures in light of fatigue damage accumulation were reviewed. Fatigue crack growth and its dependency on harsh environments were presented in detail. Additionally, apart from fatigue, several approaches to improve the reliability of MEMS were enclosed; these included creep, wear, contamination, and electrostatic discharges.

MEMS devices were once thought to be a class of the integrated circuits family as many of its fabrication and testing methods were utilized in traditional ICs technology. However, due to the unique nature of the MEMS devices, interaction with the environment, their intercomponent communication, and identification of imminent failure, the procurement of failures are still unknown at the degree of clarity.

Most MEMS devices consist of a membrane, cantilevers, and comb drives that present common failure mechanisms, for example, fatigue and stiction. Consequently, a complete understanding of these failure mechanisms can provide a platform to design and fabricate MEMS devices against potential failures. Hence academicians, research laboratories, and industry can brainstorm with lifetime, efficient, and reliable MEMS devices. This will develop the consumers' confidence on MEMS devices and thus enhance their commercialization.

\section{Conflict of Interests}

The authors have no conflict of interests.

\section{Acknowledgment}

This research is partially supported by the Ministry of Higher Education (MOHE) under cost center 15-8200-325/0135AB124.

\section{References}

[1] S. Lee, S. Park, and D. Cho, "Surface/bulk micromachining (SBM) process: a new method for fabricating released MEMS in single crystal silicon," Journal of Microelectromechanical Systems, vol. 8, no. 4, pp. 409-416, 1999.

[2] S. M. Spearing, "Materials issues in microelectromechanical systems (MEMS)," Acta Materialia, vol. 48, no. 1, pp. 179-196, 2000.

[3] O. B. Ozdoganlar, B. D. Hansche, and T. G. Carne, "Experimental modal analysis for microelectromechanical systems," Experimental Mechanics, vol. 45, no. 6, pp. 498-506, 2005.

[4] R. M. Boysel, T. G. McDonald, G. A. Magel, G. C. Smith, and J. L. Leonard Jr., "Integration of deformable mirror devices with optical fibers and waveguides," in Proceedings of the 1st Conference on Integrated Optics and Microstructure, vol. 1793, pp. 34-39, September 1992.

[5] W. Kuehnel and S. Sherman, "A surface micromachined silicon accelerometer with on-chip detection circuitry," Sensors and Actuators A, vol. 45, no. 1, pp. 7-16, 1994.

[6] M. R. Douglass, "DMD reliability: a MEMS success story”, in Proceedings of SPIE, vol. 4980, pp. 1-11, January 2003.

[7] H. Yunhan, A. Vasan, R. Doraiswami et al., "MEMS reliability review," IEEE Transactions on Device and Materials Reliability, vol. 12, pp. 482-493, 2012.

[8] S. Farhad, D. A. Hutt, and D. C. Whalley, "Application of adhesives in MEMS and MOEMS assembly: a review," in Proceedings of the 2nd International IEEE Conference on Polymers 
and Adhesives in Microelectronics and Photonics (POLYTRONIC '02), pp. 22-28.

[9] S. T. Walsh, "Roadmapping a disruptive technology: a case study The emerging microsystems and top-down nanosystems industry," Technological Forecasting and Social Change, vol. 71, no. 1-2, pp. 161-185, 2004.

[10] X. Li and B. Bhushan, "Fatigue studies of nanoscale structures for MEMS/NEMS applications using nanoindentation technique," Surface and Coatings Technology, vol. 163-164, pp. 521526,2003

[11] T.-R. Hsu, "Reliability in MEMS packaging," in Proceedings of the 44th Annual IEEE International Reliability Physics Symposium (IRPS '06), pp. 398-402, San Jose, Calif, USA, March 2006.

[12] O. Tabata and T. Tsuchiya, Eds., Reliability of MEMS, WileyVCH, Cambridge, UK, 2008.

[13] W. M. Van Spengen, "MEMS reliability from a failure mechanisms perspective," Microelectronics Reliability, vol. 43, no. 7, pp. 1049-1060, 2003.

[14] S. Ghosh and M. Bayoumi, "On integrated CMOS-MEMS system-on-chip," in Proceedings of the 3rd International IEEE Northeast Workshop on Circuits and Systems Conference (NEWCAS '05), pp. 31-34, June 2005.

[15] J. A. Walraven, "Future challenges for MEMS failure analysis," in Proceedings International Test Conference (ITC '03), pp. 850855, October 2003.

[16] D. P. Vallett, "Failure analysis requirements for nanoelectronics," IEEE Transactions on Nanotechnology, vol. 1, no. 3, pp. 117121, 2002.

[17] D. J. Fonseca and M. Sequera, "On MEMS reliability and failure mechanisms," International Journal of Quality, Statistics, and Reliability, vol. 2011, Article ID 820243, 7 pages, 2011.

[18] S. B. Brown, W. Van Arsdell, and C. L. Muhlstein, "Materials reliability in MEMS devices," in Proceedings of the 1997 International Conference on Solid-State Sensors and Actuators. Part 1 (of 2), pp. 591-593, June 1997.

[19] D. M. Tanner, J. A. Walraven, K. Helgesen et al., "MEMS reliability in shock environments," in Proceedings of the 38th IEEE International Reliability Physics Symposium, pp. 129-138, San Jose, Calif, USA, April 2000.

[20] A. L. Hartzell, M. G. da Silva, and H. Shea, MEMS Reliability, Springer, New York, NY, USA, 2011.

[21] E. Mounier, "MEMS trends," Magzine on MEMS Technologies and Markets, 2012.

[22] S. Gupta, MEMS Need Comprehensive, Market-Ready Solutions, Henkel Electronic Materials, Düsseldorf, Germany, 2013.

[23] M. S. Eldred, B. M. Adams, K. D. Copps et al., "Solutionverified reliability analysis and design of compliant microelectro-mechanical systems," in Proceedings of the 48th AIAA/ASME/ASCE/AHS/ASC Structures, Structural Dynamics, and Materials Conference (9th AIAA Non-Deterministic Approaches Conference), pp. 2881-2896, Honolulu, Hawaii, USA, April 2007.

[24] A. Broue, J. Dhennin, F. Courtade et al., "Characterization of $\mathrm{Au} / \mathrm{Au}, \mathrm{Au} / \mathrm{Ru}$, and $\mathrm{Ru} / \mathrm{Ru}$ ohmic contacts in MEMS switches improved by a novel methodology," in Proceedings of the Reliability, Packaging, Testing, and Characterization of MEMS/MOEMS and Nanodevices IX, January 2010.

[25] T.-M. Bajenescu and M. Bazu, "MEMS Manufacturing and reliability," Manufacturing Systems, vol. 7, pp. 77-82, 2012.

[26] A. Somà, "MEMS design for reliability: mechanical failure modes and testing," in Proceedings of the 7th International
Conference on Perspective Technologies and Methods in MEMS Design (MEMSTECH '11), pp. 91-101, May 2011.

[27] S. Tadigadapa and N. Najafi, "Reliability of microelectromechanical systems (MEMS)," in Proceedings of the Reliability, Testing, and Characterization of MEMS/MOEMS, vol. 4558, pp. 197-205, October 2001.

[28] F. T. Hartley, S. Arney, and F. Sexton, Microsystems Reliability, Test and Metrology, 2001.

[29] X. Xiong, Y. Wu, and W. Jone, "Reliability analysis of selfrepairable MEMS accelerometer," in Proceedings of the 21st IEEE International Symposium on Defect and Fault Tolerance in VLSI Systems (DFT '06), pp. 236-244, October 2006.

[30] X. Xiong, Y. Wu, and W. Jone, "Material fatigue and reliability of MEMS accelerometers," in Proceedings of the 23rd IEEE International Symposium on Defect and Fault Tolerance in VLSI Systems (DFT '08), pp. 314-322, October 2008.

[31] J. Bejhed, "Activity Summary Reliability assessment of a MEMSbased isolation valve for propulsion systems," 2011.

[32] H. Kam, V. Pott, R. Nathanael, J. Jeon, E. Alon, and T. K. Liu, "Design and reliability of a micro-relay technology for zerostandby-power digital logic applications," in Proceedings of the International Electron Devices Meeting (IEDM '09), pp. 1-4, December 2009.

[33] M. Bazu, L. Galateanu, and V. E. Ilian, "Reliability accelerated tests for microsystems," in Proceedings of the 34th International Spring Seminar on Electronics Technology: "New Trends in Micro/Nanotechnology” (ISSE '11), pp. 182-187, May 2011.

[34] J.-N. Hung, H. Hocheng, and K. Sato, "Torsion fatigue testing of polycrystalline Silicon cross-micro bridge structures," Japnaese Journal of Applied Physics, vol. 50, no. 6, Article ID 06GM07, pp. $1-5,2011$.

[35] A. Bemis, A. Ned, S. Stefanescu, N. Wilson, and A. Kane, "The effect of silicon fatigue on Kulite silicon pressure sensor's reliability," Kulite Proprietary Information, 2012.

[36] X. J. Liang and S. Q. Gao, "The adhesion failure analysis of the MEMS gyroscope with comb capacitor," in Proceedings of the 8th International Conference on Reliability, Maintainability and Safety (ICRMS '09), pp. 1234-1236, July 2009.

[37] C. Patel, P. McCluskey, and D. Lemus, "Performance and reliability of MEMS gyroscopes at high temperatures," in Proceedings of the 12th IEEE Intersociety Conference on Thermal and Thermomechanical Phenomena in Electronic Systems (ITherm '10), pp. 1-5, June 2010.

[38] M. Budnitzki, M. C. Scates, R. O. Ritchie, E. A. Stach, C. L. Muhlstein, and O. N. Pierron, "The effects of cubic stiffness on fatigue characterization resonator performance," Sensors and Actuators A, vol. 157, no. 2, pp. 228-234, 2010.

[39] D. Mardivirin, A. Pothier, M. E. Khatib, A. Crunteanu, O. Vendier, and A. Blondy, "Reliability of dielectric less electrostatic actuators in RF-MEMS ohmic switches," in Proceedings of the European Microwave Integrated Circuit Conference (EuMIC '08), pp. 490-493, October 2008.

[40] F. A. Boloni, A. Benabou, and A. Tounzi, "Stochastic modeling of the pull-in voltage in a MEMS beam structure," IEEE Transactions on Magnetics, vol. 47, no. 5, pp. 974-977, 2011.

[41] G. X. Li and F. A. Shemansky Jr., "Drop test and analysis on micro-machined structures," Sensors and Actuators A, vol. 85, no. 1, pp. 280-286, 2000.

[42] A. Beliveau, G. T. Spencer, K. A. Thomas, and S. L. Roberson, "Evaluation of MEMS capacitive accelerometers," IEEE Design \& Test of Computers, vol. 16, no. 4, pp. 48-56, 1999. 
[43] T. G. Brown, B. Davis, D. Hepner et al., "Strap-down microelectromechanical (MEMS) sensors for high-G munition applications," IEEE Transactions on Magnetics, vol. 37, no. 1, pp. 336342,2001

[44] X. Fang, Q. Huang, and J. Tang, "Modeling of MEMS reliability in shock environments," in Proceedings of the 7th International Conference on Solid-State and Integrated Circuits Technology Proceedings (ICSICT '04), pp. 860-863, October 2004.

[45] Q. Zhang, X. Guo, Y. Liu, N. Dai, and P. Lu, "Corrosion and fatigue in micro-sized Ni cantilever beams," Transactions of Nonferrous Metals Society of China, vol. 17, pp. 213-217, 2007.

[46] "Metals handbook (desk edition) chapter 32 (failure analysis)," in American Society for Metals, vol. 32, pp. 24-26, ASM International, Novelty, Ohio, USA, 1997.

[47] T. Yi and C. Kim, "Measurement of mechanical properties for MEMS materials," Measurement Science and Technology, vol. 10, no. 8, pp. 706-716, 1999.

[48] S. M. Ali and L. M. Phinney, "Investigation of adhesion during operation of MEMS cantilevers," in Proceedings of the Reliability, Testing, and Characterization of MEMS/MOEMS III, pp. 215226, January 2004.

[49] N. S. Tambe and B. Bhushan, "Scale dependence of micro/nanofriction and adhesion of MEMS/NEMS materials, coatings and lubricants," Nanotechnology, vol. 15, no. 11, pp. 1561-1570, 2004.

[50] J. K. Luo, Y. Q. Fu, H. R. Le, J. A. Williams, S. M. Spearing, and W. I. Milne, "Diamond and diamond-like carbon MEMS," Journal of Micromechanics and Microengineering, vol. 17, supplement 7, pp. S147-S184, 2007.

[51] S. A. Smallwood, K. C. Eapen, S. T. Patton, and J. S. Zabinski, "Performance results of MEMS coated with a conformal DLC," Wear, vol. 260, no. 11-12, pp. 1179-1189, 2006.

[52] Z. Guo, Z. Feng, S. Fan, D. Zheng, and H. Zhuang, "Research development of measuring methods on the tribology characters for movable MEMS devices: a review," Microsystem Technologies, vol. 15, no. 3, pp. 343-354, 2009.

[53] J. A. Walraven, "Failure mechanisms in MEMS," in Proceedings International Test Conference (ITC '03), pp. 828-833, October 2003.

[54] C. Duvvury and A. Amerasekera, "ESD. A pervasive reliability concern for IC technologies," Proceedings of the IEEE, vol. 81, no. 5, pp. 690-702, 1993.

[55] G. M. Rebeiz and J. B. Muldavin, "RF MEMS switches and switch circuits," IEEE Microwave Magazine, vol. 2, no. 4, pp. 5971, 2001.

[56] J. DeNatale, R. Mihailovich, and J. Waldrop, “Techniques for reliability analysis of MEMS RF switch," in Proceedings of the 2002 40th annual IEEE International Relaibility Physics Symposium, pp. 116-117, April 2002.

[57] M. Kaynak, F. Korndörfer, M. Wietstruck et al., "Robustness and reliability of BiCMOS embedded RF-MEMS switch," in Proceedings of the IEEE 11th Topical Meeting on Silicon Monolithic Integrated Circuits in RF Systems (SiRF '11), pp. 177-180, January 2011.

[58] B. Stark, Ed., MEMS Reliability Assurance Guidelines for Space Applications, JPL Publication, Pasadena, Calif, USA, 1999.

[59] S. S. McClure, L. D. Edmonds, R. Mihailovich et al., "Radiation effects in micro-electromechanical systems (MEMS): RF relays," IEEE Transactions on Nuclear Science, vol. 49, no. 6, pp. 31973202, 2002.

[60] H. S. Newman, J. L. Ebel, D. Judy, and J. Maciel, "Lifetime measurements on a high-reliability RF-MEMS contact switch,"
IEEE Microwave and Wireless Components Letters, vol. 18, no. 2, pp. 100-102, 2008.

[61] I. D. Wolf, MEMS Reliability Testing, Micro and Nano Systems, Lanchaster, UK, 2007.

[62] R. Pathak, S. Joshi, and D. K. Mishra, "Distributive computing for reliability analysis of MEMS devices using MATLAB," in Proceedings of the International Conference on Advances in Computing, Communication and Control (ICAC '09), pp. 246250, January 2009.

[63] Q. Sun, Y. Tang, J. Feng, and P. Kvam, "Stress-lifetime joint distribution model for performance degradation failure," in Proceedings of the International Conference on Quality, Reliability, Risk, Maintenance, and Safety Engineering (ICQR2MSE '11), pp. 308-311, June 2011.

[64] I. Guttman, S. Wilks, and J. S. Hunter, Eds., Introductory Engineering Statistics, John Wiley \& Sons, New York, NY, USA, 1982.

[65] F. R. Nash, Ed., Estimating Device Reliability: Assessment of Credibility (The Springer International Series in Engineering and Computer Science), The Springer International Series in Engineering and Computer Science, Kluwer Academic, New York, NY, USA, 1993.

[66] J. I. McCool, Ed., Using the Weibull Distribution: Reliability, Modeling and Inference, Wiley, New York, NY, USA, 2012.

[67] D. R. Abernethy, Ed., The New Weibull Handbook Fifth Edition, Reliability and Statistical Analysis for Predicting Life, Safety, Supportability, Risk, Cost and Warranty Claims, Amazon, Luxembourg, 2000.

[68] D. M. Tanner, J. A. Walraven, L. W. Irwin et al., "Effect of humidity on the reliability of a surface micromachined microengine," in Proceedings of the 1999 37th Annual IEEE International Reliability Physics Symposium, pp. 189-197, San Diego, Calif, USA, March 1999.

[69] F. Su, W. Hwang, A. Mukherjee, and K. Chakrabarty, "Defectoriented testing and diagnosis of digital microfluidics-based biochips," in Proceedings of the IEEE International Test Conference (ITC '05), pp. 487-496, November 2005.

[70] H. Kapels, R. Aigner, and J. Binder, "Fracture strength and fatigue of polysilicon determined by a novel thermal actuator," IEEE Transactions on Electron Devices, vol. 47, no. 7, pp. 15221528, 2000.

[71] M. van Gils, J. Bielen, and G. McDonald, "Evaluation of creep in RF MEMS devices," in Proceedings of the International Conference on Thermal, Mechanical and Multi-Physics Simulation Experiments in Microelectronics and Micro-Systems (EuroSime '07), pp. 1-7, April 2007.

[72] Q. Min, J. Tao, Y. Zhang, and X. Chen, "A parallel-plate actuated test structure for fatigue analysis of MEMS," in Proceedings of the International Conference on Quality, Reliability, Risk, Maintenance, and Safety Engineering (ICQR2MSE '11), pp. 297301, June 2011.

[73] S. M. Ali, S. C. Mantell, and E. K. Longmire, "Experimental technique for fatigue testing of MEMS in liquids," Journal of Microelectromechanical Systems, vol. 21, no. 3, pp. 520-522, 2012.

[74] F. A. Boloni, A. Benabou, and A. Tounzi, "Stochastic modeling of the pull-in voltage in a MEMS beam structure," IEEE Transactions on Magnetics, vol. 47, no. 5, pp. 974-977, 2011.

[75] D. Mardivirin, A. Pothier, M. E. Khatib, A. Crunteanu, O. Vendier, and A. Blondy, "Reliability of dielectric less electrostatic actuators in RF-MEMS ohmic switches," in Proceedings of the European Microwave Integrated Circuit Conference (EuMIC '08), pp. 490-493, October 2008. 
[76] P. Yang and N. Liao, "Surface sliding simulation in microgear train for adhesion problem and tribology design by using molecular dynamics model," Computational Materials Science, vol. 38, no. 4, pp. 678-684, 2007.

[77] J. A. Walraven, "Failure analysis issues in microelectromechanical systems (MEMS)," Microelectronics Reliability, vol. 45, no. 9-11, pp. 1750-1757, 2005.

[78] H. R. Shea, A. Gasparyan, H. B. Chan et al., "Effects of electrical leakage currents on MEMS reliability and performance," IEEE Transactions on Device and Materials Reliability, vol. 4, no. 2, pp. 198-207, 2004.

[79] S. W. Yoona, S. Leea, and K. Najafia, "Vibration-induced errors in MEMS tuning fork gyroscopes," Sensors and Actuators A, vol. 180, pp. 32-44, 2012.

[80] O. Matviykiv and M. Lobur, "Design principles and sensitivity analysis of MEMS cantilever sensors," in Proceedings of the 6th International Conference of Young Scientists "Perspective Technologies and Methods in MEMS Design" (MEMSTECH '10), pp. 230-232, April 2010.

[81] P. S. Thakur, K. Sugano, T. Tsuchiya, and O. Tabata, "Analysis of acceleration sensitivity in MEMS tuning fork gyroscope," in Proceedings of the 16th International Solid-State Sensors, Actuators and Microsystems Conference (TRANSDUCERS '11), pp. 2006-2009, June 2011.

[82] G. Baeten and H. van der Heijden, "Improving $\mathrm{S} / \mathrm{N}$ for high frequencies," Leading Edge, vol. 27, no. 2, pp. 144-153, 2008.

[83] M. T. Jan, A. Iqbal, and M. Shoaib, "An unconventional method for exploration of oil and gas," in Proceedings of the International Conference on Emerging Technologies (ICET '12), pp. 1-5, 2012.

[84] Y. C. Lin, H. Hocheng, W. L. Fang, and R. Chen, "Fabrication and fatigue testing of an electrostatically driven microcantilever beam," Materials and Manufacturing Processes, vol. 21, no. 1, pp. 75-80, 2006.

[85] P. Shrotriya, S. M. Allameh, and W. O. Soboyejo, "On the evolution of surface morphology of polysilicon MEMS structures during fatigue," Mechanics of Materials, vol. 36, no. 1-2, pp. 3544, 2004.

[86] T. Tsuchiya, A. Inoue, J. Sakata, M. Hashimoto, A. Yokoyame, and M. Sugimoto, "Fatigue test of single crystal silicon resonator," in Proceedings of the Technical Digest of the 11th Sensor Symposium, pp. 277-280, Tokyo, Japan, 1998.

[87] T. Ikehara and T. Tsuchiya, "Low-cycle to ultrahigh-cycle fatigue lifetime measurement of single-crystal-silicon specimens using a microresonator test device," Journal of Microelectromechanical Systems, vol. 21, no. 4, pp. 830-840, 2012.

[88] R. E. Boroch, R. Müller-Fiedler, J. Bagdahn, and P. Gumbsch, "High-cycle fatigue and strengthening in polycrystalline silicon," Scripta Materialia, vol. 59, no. 9, pp. 936-940, 2008.

[89] G. Langfelder, A. Longoni, F. Zaraga, A. Corigliano, A. Ghisi, and A. Merassi, "A new on-chip test structure for real time fatigue analysis in polysilicon MEMS," Microelectronics Reliability, vol. 49, no. 2, pp. 120-126, 2009.

[90] H. Kahn, R. Ballarini, and A. H. Heuer, "Dynamic fatigue of silicon," Current Opinion in Solid State and Materials Science, vol. 8, no. 1, pp. 71-76, 2004.

[91] H. Hong, J. Hung, and Y. Guu, "Various fatigue testing of polycrystalline silicon microcantilever beam in bending," Japanese Journal of Applied Physics, vol. 47, no. 6, pp. 5256-5261, 2008.

[92] K. Bhalerao, A. B. O. Soboyejo, and W. O. Soboyejo, "Modeling of fatigue in polysilicon MEMS structures," Journal of Materials Science, vol. 38, no. 20, pp. 4157-4161, 2003.
[93] B. Jalalahmadi, F. Sadeghi, and D. Peroulis, "A numerical fatigue damage model for life scatter of MEMS devices," Journal of Microelectromechanical Systems, vol. 18, no. 5, pp. 1016-1031, 2009.

[94] S. M. Allameh, B. Gally, S. Brown, and W. O. Soboyejo, "Surface topology and fatigue in Si MEMS structures," in Proceedings of the Mechanical Properties of Structural Films, pp. 3-15, November 2000.

[95] Y.-1. lee, J. Pan, R. Hathaway, and M. Barkey, Eds., Fatigue Testing and Analysis (Theory and Practice), Butterworth-Heinemann, Elsevier, New York, NY, USA, 2005.

[96] W. W. van Arsdell and S. B. Brown, "Subcritical crack growth in silicon MEMS," Journal of Microelectromechanical Systems, vol. 8, no. 3, pp. 319-327, 1999.

[97] R. Zheng and A. Pendharkar, "Obstacle discovery in distributed active sensor networks," in Proceedings of the 28th Conference on Computer Communications (IEEE INFOCOM '09), pp. 909-917, April 2009.

[98] N. Pugno, M. Ciavarella, P. Cornetti, and A. Carpinteri, "A generalized Paris' law for fatigue crack growth," Journal of the Mechanics and Physics of Solids, vol. 54, no. 7, pp. 1333-1349, 2006.

[99] S. J. Chu and C. Liu, "Finite element simulation of fatigue crack growth: determination of the Paris exponent," in Proceedings of the 6th International Forum on Strategic Technology (IFOST '11), pp. 15-19, August 2011.

[100] A. D. Romig Jr., M. T. Dugger, and P. J. McWhorter, "Materials issues in microelectromechanical devices: science, engineering, manufacturability and reliability," Acta Materialia, vol. 51, no. 19, pp. 5837-5866, 2003.

[101] Z. Stanimirovic and I. Stanimirovic, "Mechanical characterization of MEMS materials," in Proceedings of the 28th International Conference on Microelectronics (MIEL), pp. 177-179, 2012.

[102] A. B. O. Soboyejo, K. D. Bhalerao, and W. O. Soboyejo, "Reliability assessment of polysilicon MEMS structures under mechanical fatigue loading," Journal of Materials Science, vol. 38, no. 20, pp. 4163-4167, 2003.

[103] K. E. Petersen, "Silicon as a mechanical material," Proceedings of the IEEE, vol. 70, no. 5, pp. 420-457, 1982.

[104] T. Ikehara and T. Tsuchiya, "High-cycle fatigue of micromachined single-crystal silicon measured using high-resolution patterned specimens," Journal of Micromechanics and Microengineering, vol. 18, no. 7, Article ID 075004, pp. 1371-1386, 2008.

[105] C. L. Muhlstein, R. T. Howe, and R. O. Ritchie, "Fatigue of polycrystalline silicon for microelectromechanical system applications: crack growth and stability under resonant loading conditions," Mechanics of Materials, vol. 36, no. 1-2, pp. 13-33, 2004.

[106] D. H. Alsem, R. Timmerman, B. L. Boyce, E. A. Stach, J. T. M. De Hosson, and R. O. Ritchie, "Very high-cycle fatigue failure in micron-scale polycrystalline silicon films: effects of environment and surface oxide thickness," Journal of Applied Physics, vol. 101, no. 1, Article ID 013515, 2007.

[107] O. N. Pierron and C. L. Muhlstein, "Notch root oxide formation during fatigue of polycrystalline silicon structural films," Journal of Microelectromechanical Systems, vol. 16, no. 6, pp. 14411450, 2007.

[108] C. L. Muhlstein, E. A. Stach, and R. O. Ritchie, "A reaction-layer mechanism for the delayed failure of micron-scale polycrystalline silicon structural films subjected to high-cycle fatigue loading," Acta Materialia, vol. 50, no. 14, pp. 3579-3595, 2002. 
[109] H. Kahn, R. Ballarini, J. J. Bellante, and A. H. Heuer, "Fatigue failure in polysilicon not due to simple stress corrosion cracking," Science, vol. 298, no. 5596, pp. 1215-1218, 2002.

[110] S. M. Allameh, P. Shrotriya, A. Butterwick, S. B. Brown, and W. O. Soboyejo, "Surface topography evolution and fatigue fracture in polysilicon MEMS structures," Journal of Microelectromechanical Systems, vol. 12, no. 3, pp. 313-324, 2003.

[111] S. Yamashita, H. Wado, Y. Takeuchi, T. Tsuchiya, and O. Tabata, "Fatigue characteristics of polycrystalline silicon thinfilm membrane and its dependence on humidity," Journal of Micromechanics and Microengineering, vol. 23, no. 3, pp. 1-11, 2013.

[112] p. olovier, "Environmental contributions to fatigue failure of micron-scale silicon films used in microelectromechanical system (MEMS) devices," Intercollege Graduate Program in Materials, The Pennsylvania State University, University Park, Pa, USA, 2005.

[113] Y. Yamaji, K. Sugano, O. Tabata, and T. Tsuchiya, “Tensile-mode fatigue tests and fatigue life predictions of single crystal silicon in humidity controlled environments," in Proceedings of the 20th IEEE International Conference on Micro Electro Mechanical Systems (MEMS '07), pp. 267-270, January 2007.

[114] P. M. Sousa, V. Chu, and J. P. Conde, "Reliability and stability of thin-film amorphous silicon MEMS resonators," Journal of Micromechanics and Microengineering, vol. 22, no. 6, pp. 1-8, 2012.

[115] W. N. Sharpe Jr., J. Bagdahn, K. Jackson, and G. Coles, "Tensile testing of MEMS materials-recent progress," Journal of Materials Science, vol. 38, no. 20, pp. 4075-4079, 2003.

[116] J. Bagdahn and W. N. Sharpe Jr., "Fatigue of polycrystalline silicon under long-term cyclic loading," Sensors and Actuators A, vol. 103, no. 1-2, pp. 9-15, 2003.

[117] S. Kamiya, S. Amaki, T. Kawai et al., "Seamless interpretation of the strength and fatigue lifetime of polycrystalline silicon thin films," Journal of Micromechanics and Microengineering, vol. 18, no. 9, Article ID 095023, 2008.

[118] H. Kahn, R. Ballarini, R. L. Mullen, and A. H. Heuer, "Electrostatically actuated failure of microfabricated polysilicon fracture mechanics specimens," Proceedings of the Royal Society A, vol. 455, no. 1990, pp. 3807-3823, 1999.

[119] C. L. Muhlstein, S. B. Brown, and R. O. Ritchie, "High-cycle fatigue and durability of polycrystalline silicon thin films in ambient air," Sensors and Actuators A, vol. 94, no. 3, pp. 177-188, 2001.

[120] A. M. Fitzgerald, D. M. Pierce, B. M. Huigens, and C. D. White, "A general methodology to predict the reliability of singlecrystal silicon MEMS devices," Journal of Microelectromechanical Systems, vol. 18, no. 4, pp. 962-970, 2009.

[121] T. Ikehara and T. Tsuchiya, "High-cycle fatigue of micromachined single crystal silicon measured using a parallel fatigue test system," IEICE Electronics Express, vol. 4, no. 9, pp. 288-293, 2007.

[122] M. Budnitzki and O. N. Pierron, "Highly localized surface oxide thickening on polycrystalline silicon thin films during cyclic loading in humid environments," Acta Materialia, vol. 57, no. 10, pp. 2944-2955, 2009.

[123] E. K. Baumert, P.-O. Theillet, and O. N. Pierron, "Investigation of the low-cycle fatigue mechanism for micron-scale monocrystalline silicon films," Acta Materialia, vol. 58, no. 8, pp. 28542863, 2010.
[124] T. Namazu and Y. Isono, "Fatigue life prediction citerion for micro-nanoscale single-crystal silicon structures," Journal of Microelectromechanical Systems, vol. 18, no. 1, pp. 129-137, 2009.

[125] J.-N. Hung and H. Hocheng, "Frequency effects and life prediction of polysilicon microcantilever beams in bending fatigue," Journal of Micro/Nanolithography, MEMS, and MOEMS, vol. 11, no. 2, Article ID 021206, 2012.

[126] S. Kamiya, Y. Ikeda, J. Gaspar, and O. Paul, "Effect of humidity and temperature on the fatigue behavior of polysilicon thin film," Sensors and Actuators A, vol. 170, no. 1-2, pp. 187-195, 2011. 

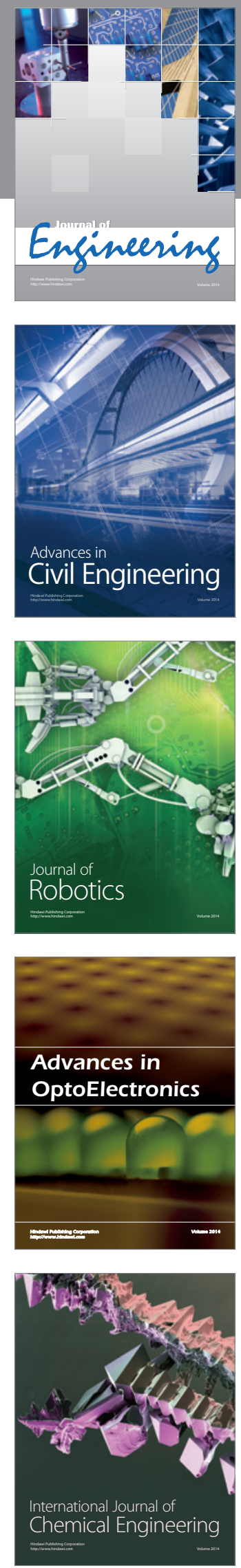

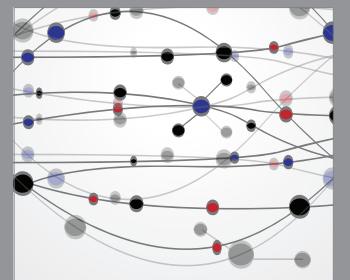

The Scientific World Journal
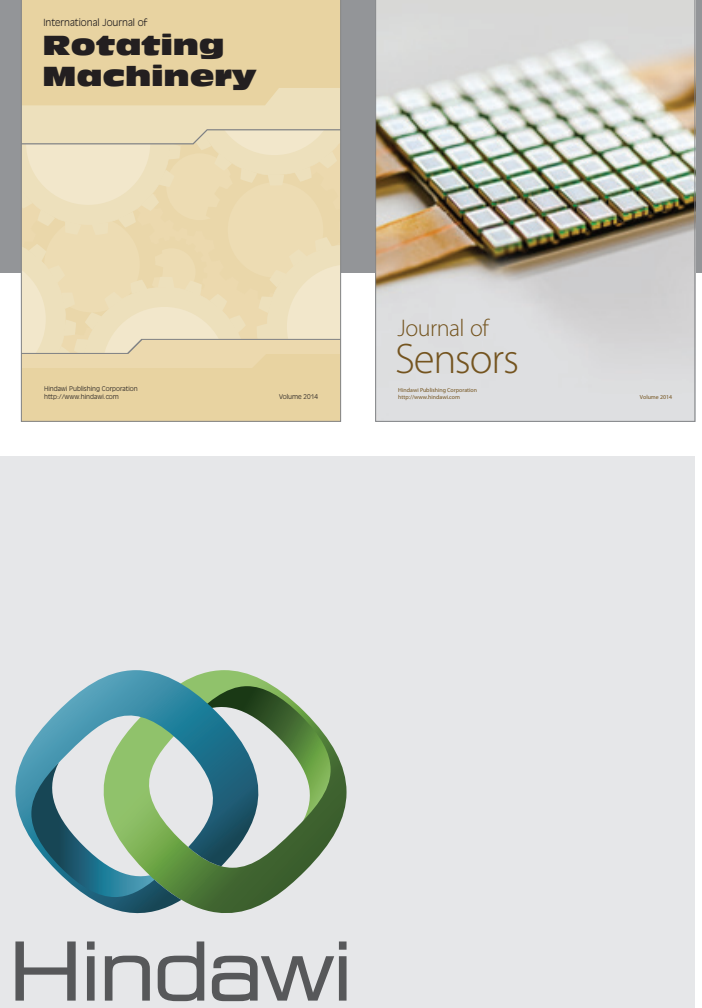

Submit your manuscripts at http://www.hindawi.com
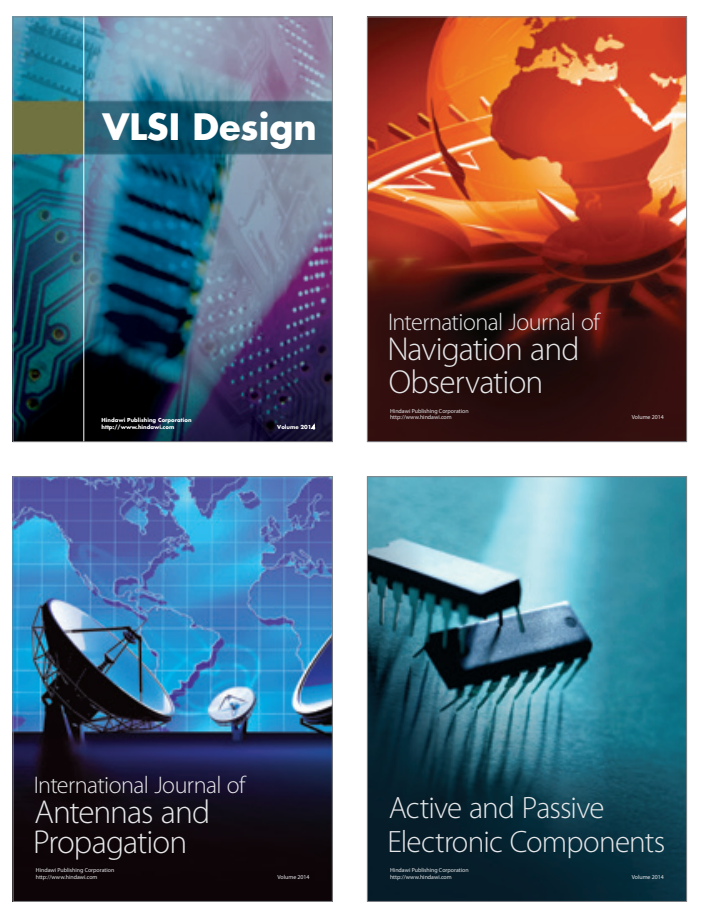
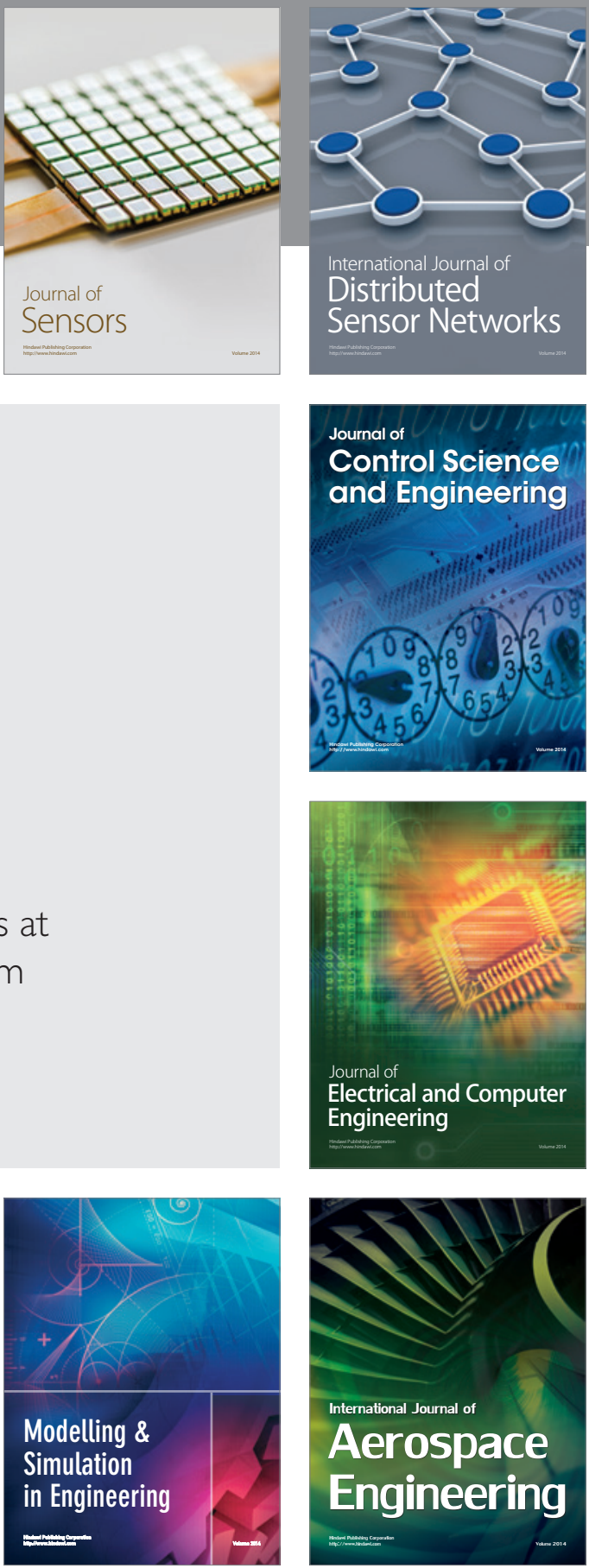

Journal of

Control Science

and Engineering
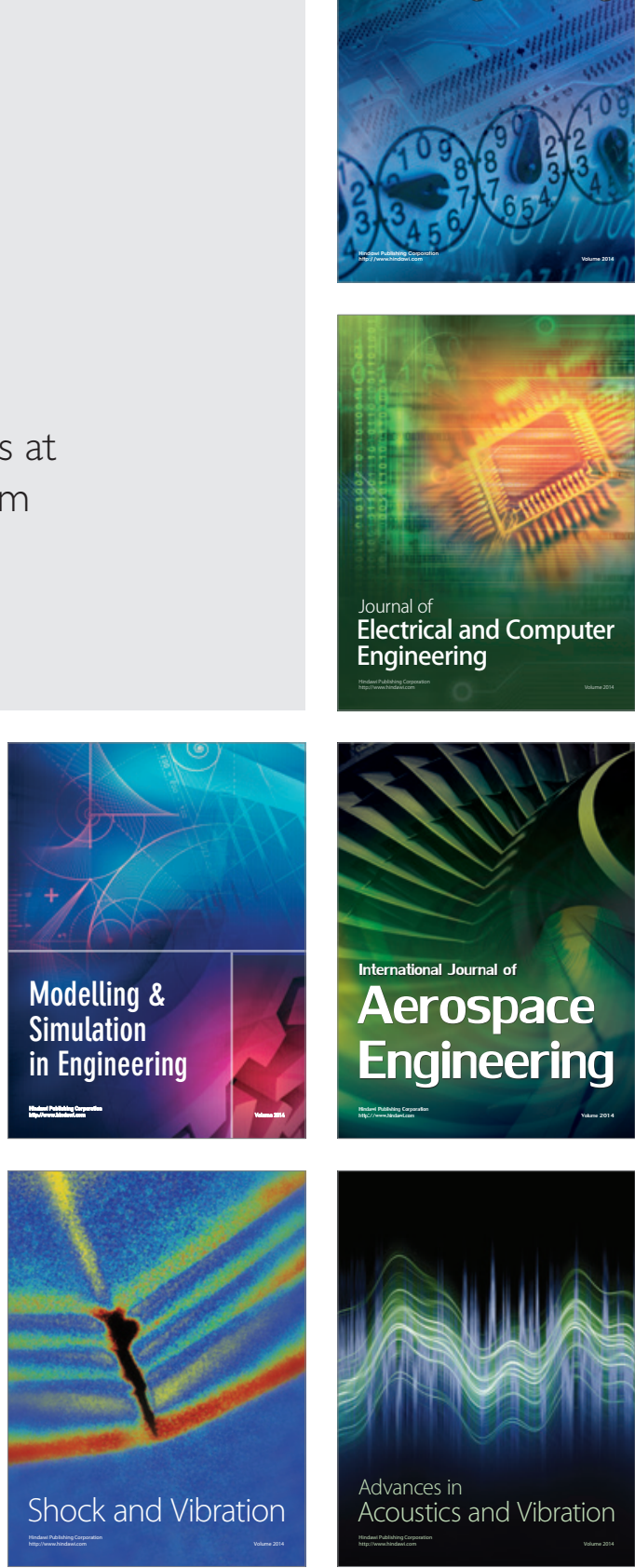